\title{
Fire history of an inhabited Earth: Experiences from the PAGES Global Paleofire Working Group
}

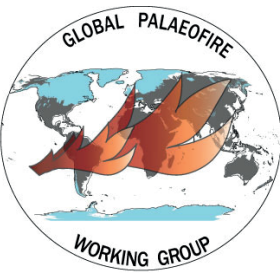

Boris Vannière ${ }^{1,2}$, D. Colombaroli ${ }^{3}$ and M.J. Power ${ }^{4,5}$

\section{Paleofire research, which was the focus of the PAGES Global Paleofire Working Group over the past 12 years, offers a unique approach to understanding the environmental and social implications of large-scale disturbances associated with changing fire regimes at regional and continental scales.}

Recent episodes of destructive fires, seen in media worldwide, have been referred to as "mega-fires" (Williams 2013). In the past decade, nearly every continent has experi enced fires of unusual magnitude, calling into question humanity's ability to accept fire as a natural process with which we should coexist (Moritz et al. 2014). Fire scientists are beginning to recognize how humans have been responsible, in many ways, for patterns and consequences of fire occurrence that pervade ecosystems today. Even more critical is acknowledging how our species has progressively promoted conditions for fires to occur over the past centuries and millennia by the sustained conversion of landscapes into fire-prone ecosystems. Humans have become one of the greatest sources of fire while simultaneously creating more fireprone weather through changing the Earth's climate (Pyne 2015)

\section{Global Paleofire Working Group}

Over the past two decades, the number of scientific papers on past fire regimes has increased steadily (e.g. Aleman et al. 2018). Some of these publications were products of an ambitious research project driven by the PAGES Global Paleofire Working Group (GPWG; Power et al. 2008a; Vannière et al. 2016a). Indeed, the long-term perspective offered by paleofire research provides a unique approach to understanding environmental dynamics through time, including the ecological consequences of large-scale disturbances like mega-fires. Such long-term perspectives highlight the multiple factors driving fire regimes and capture the longlasting effects on ecosystems.

Improving our knowledge of ecological legacies is one of the many opportunities that paleoarchives offer (Whitlock et al. 2010; Power and Vannière 2018). Ecologists have long understood that fire regimes evolve over long timescales, often beyond the ability of modern observations to disentangle forcings and responses, justifying the need for paleofire perspectives. This is most evident in recent trends of increased occurrence of catastrophic fires, emphasizing the critical need to understand and contextualize these transformative processes in the modern world. Interrogating and disseminating knowledge on the history of fire and its role in shaping ecosystems is a fundamental objective for maintaining a habitable Earth where all species may thrive, despite the destructive nature of these fine-scale processes with global consequences.

The GPWG was formally launched in 2008 after several years of collaborative work around the implementation of a global fire history database (Power et al. 2008b; Marlon et al. 2008). The main objective was to centralize a growing volume of fire history data, scattered throughout publications, laboratories and research programs around the world. This unique dataset made novel estimations of millennial-scale changes in biomass burning at global scales possible as fire scientists began to understand the causes and responses of those changes (e.g. Marlon et al. 2013; Vannière et al. 2016b). This empirically based understanding of fire allowed GPWG to test new hypotheses while evaluating and improving climate models that integrate fire as a key element of the global carbon cycle (Harrison et al. 2018). Additionally, global paleofire data have become a critical resource for estimating the probability of fire occurrence under the constraints of past and future climate change scenarios (Daniau et al. 2012; Lestienne et al. 2020).

The GPWG operated for 12 years in two distinct phases (Power et al. 2008a; Vannière et al. 2016a): GPWG (2008-2015) and GPWG2 (2016-2019). During this time, 18 workshops and congress sessions were organized in 11 countries and 16 cities, bringing together scholars from more than 60 countries (Fig. 1). Based on these scientific meetings, which ranged from day-long to week-long events, more than 50 scientific papers emerged from the new collaborations promoted by the GPWG. PAGES news and Past Global Changes Magazine published 12 meetingoutcome papers and dedicated a full issue to paleofire research (Whitlock et al. 2010), including topics such as regional paleofire reconstructions, calibration, and data-model comparisons. A full issue of Quaternary International reported on the PAGES-GPWG session at INQUA 2015 at Nagoya, Japan (Power and Vannière 2018).

The main objectives of the community workshops were to collectively define priority research areas in paleofire science, to collect data through the sharing of the regional expertise of the participants, to support the emergence of early-career researchers, and to reach out to as many researchers as possible from countries where paleofire research had received limited support.

\section{Data, expertise, and outreach}

As the GPWG transitioned from the early community-growth phase into phase two new challenges and research agendas emerged. During the workshops of the GPWG2 phase, a reflection on intellectual gaps in knowledge and a need for additional collaborative work was carried out with a focus on targeting policy makers and
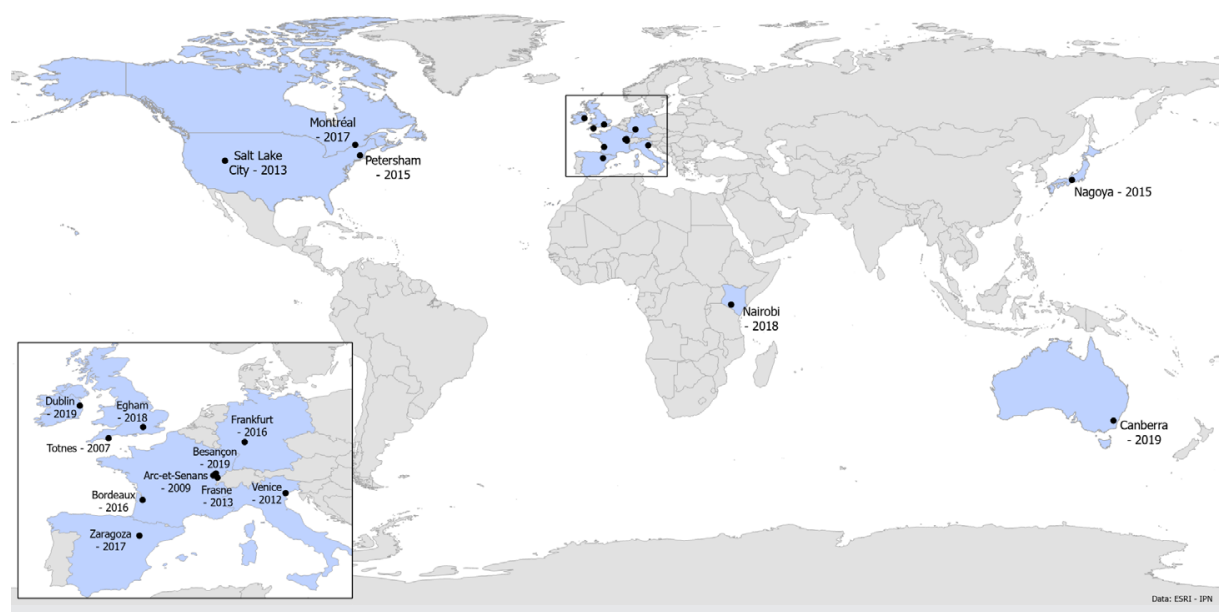

Figure 1: Location of Global Paleofire Working Group workshops and congress sessions over the past 12 years. 
environmental managers. The priority for GPWG2 was to apply and transmit scholarly research into action, by emphasizing theoretical reference frames and quantified estimates of biomass burning, and by connecting areas of expertise on longterm environmental processes associated with past and current fire regime changes (Marcisz et al. 2018). One of the long-standing challenges in this community has been the integration of more applied research in communicating with stakeholders. In 2019, the GPWG released a first policy brief (Colombaroli et al. 2019) to identify best practices for sustainable ecosystem management, including how transdisciplinary knowledge (such as paleoecology and Indigenous knowledge) can better inform fire management and policy.

As the paleofire community has evolved, knowledge has been acquired about the drivers and circumstances of fire regimes, the role of anthropogenic fire practices since prehistoric times, and fire ecology on a range of spatial and temporal scales. Translating this knowledge for practitioners has opened new dialogs on sustainable fire risk preparedness. Since fire is viewed by many as a dramatic and dangerous phenomenon, it naturally raises societal fears. Considerable national and local resources are focused on firefighting and suppression policies, which, unfortunately, in the current context of global change, have become insufficient for protecting human populations and the resources we depend on. Moreover, fire was the first of the natural elements - water, earth, fire, and air - to have been significantly altered by our species. Unlike most other elements, fire transcends spatial scales, from the smallest hearth to the largest mega-fires, and operates on all temporal scales, from rapidly changing ecosystems over a few minutes to shaping landscapes over millennia (Pyne 2015).

The large majority of the work and results facilitated by the GPWG are based on the Global Paleofire Database (https://database. paleofire.org). The original goal of the Global Charcoal Database was to integrate all dated, quantitative sedimentary fire-history series (i.e. records of sedimentary charcoal) previously published in the scientific literature. Numerous efforts were put forth to synthesize and compare these fire-history series at regional, continental, and global scales to reconstruct temporal changes in biomass burning (Power et al. 2008b; Vannière et al. 2014).

\section{Fire history, drivers, and impacts}

Several key discoveries have emerged over the past decade because of these efforts. The first lesson was that for a very large majority of the world's ecosystems, biomass burning has increased continuously since the Last Glacial Maximum ( 21,000 years ago) in response to long-term changes in (1) climate; (2) vegetation, i.e. the amount of biomass available; and (3) human land use. In contrast to the last ice age when the fire signal was very weak in most of the world's ecosystems, the Holocene shows increased spatial
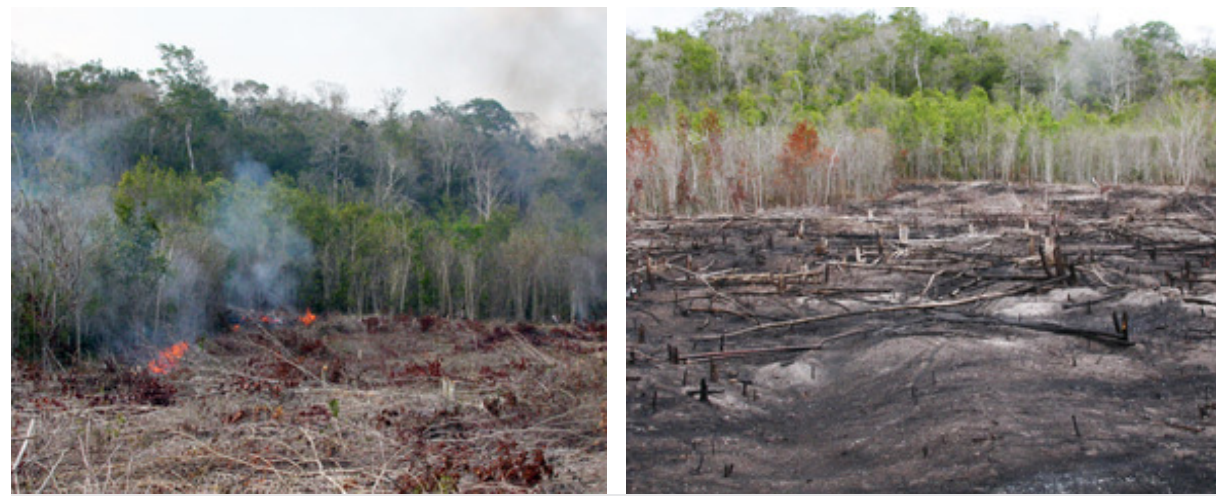

Figure 2: A slash-and-burn plot in the tropical dry forest of south-Yucatan, Mexico (Image credit: Boris Vannière, 2004).

heterogeneity in fire activity from one region of the globe to another (Power et al. 2008b).

A second lesson from these efforts was that increasing temperatures is the most important driver of past fire activity. Additionally, abrupt increases in fire activity are linked to intermediate moisture levels that, on the one hand, favor vegetation growth and, on the other hand, can lead to periods of fire-prone drought (Colombaroli et al. 2014; Daniau et al. 2012). For example, during the last glacialinterglacial transition, and at the beginning of the Holocene, a time of maximum solar insolation, many ecosystems on the planet burned regularly, depending on the biomass availability, and in a relatively sustained manner when compared to the modern period (for example Lestienne et al. 2020).

A third lesson has emerged about the role of anthropogenic fire: during the middle and late Holocene, vegetation communities were increasingly modified by human activities; at this time, anthropogenic activities began to override climate as the major player in maintaining and modifying fire regimes in many ecosystems. Evidence from the boreal region (Blarquez et al. 2015), the equatorial region (Colombaroli et al. 2014), the temperate region in Europe (Dietze et al. 2018), and the Mediterranean (Vannière et al. 2016b) supports these findings.

Perhaps the most significant lesson derived from the efforts of the GPWG was that across the planet's biomes and ecosystems, it remains challenging to disentangle natural from anthropogenic drivers of fire and related feedbacks. Similarly, it is still unclear whether vegetation ultimately drives a particular type of fire regime or whether the introduction of fire encourages the expansion of fire-adapted plant formations (Feurdean et al. 2020). However, the emerging collaborative work on these challenges suggests that following a shift in fire regime and/or vegetation composition, a new dynamic balance is established, at least until changes in climate and/or human activities disrupt the system once again.

\section{Lessons from the past}

Today, paleofire research suggests that the spatial expression of burning has become more regionally heterogeneous throughout the past 10,000 years, particularly as humans increasingly altered natural fire regimes
(Fig. 2). Although the precise timing and regional chronologies of human impacts on fire remain highly variable in space, these findings agree with regional histories of land colonization and cultural changes (Connor et al. 2019). Increasing evidence for regional and even continental-scale human-fire legacies on long timescales are beginning to question old paradigms (Blarquez et al. 2015; Colombaroli et al. 2014).

For example, in Europe, the human footprint on fire regimes extends at least to the beginning of the Neolithic period, i.e. between 9000 and 7000 years ago (Dietze et al. 2018). This may have taken the form of increased fire frequency in exploited ecosystems, which indirectly caused a decrease in the magnitude of large-scale events (extent and intensity). As landscapes became more fragmented, fuel loads were altered and fire regimes were permanently changed from pre-human intervention. (Fig. 3; Vannière et al. 2016b).

Novel fire and vegetation reconstructions are also challenging assumptions regarding biodiversity. It has recently been recognized for example, that human activities may promote and maintain optimum fire conditions, which in turn maximize plant diversity in ecosystems; in this way, long-term anthropogenic behavior can have a positive impact on biodiversity. For example, in the Iberian Peninsula, Connor et al. (2019) demonstrated that changes in fire regime and vegetation diversity correspond with long-term humanenvironment interactions beginning as early as 7500 years ago. This new evidence suggests that Neolithic burning promoted veg etation openness and increased woodland diversity $\sim 5000$ years and again $\sim 2000$ years ago, when intensification and acceleration of the human landscape transformation led to permanent transitions in ecosystem state. In this case, human-driven fires favored open vegetation diversity, disrupted woodland diversity, and meaningfully decreased landscape richness on a regional scale.

During the Holocene, the frequency, size, and intensity of fires may have been much greater or more intense than even the "mega-fires" observed in recent years (Lestienne et al. 2020). The media's portrayal of mega-fires promotes frightening news summaries with discussions of the unprecedented nature of recent events. 
(a)

BIOMASS BURNED normalized, sd units

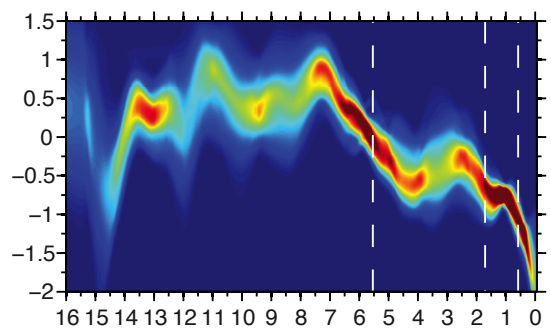

Age kyr cal BP

\section{FIRE FREQUENCY fire episodes per year}

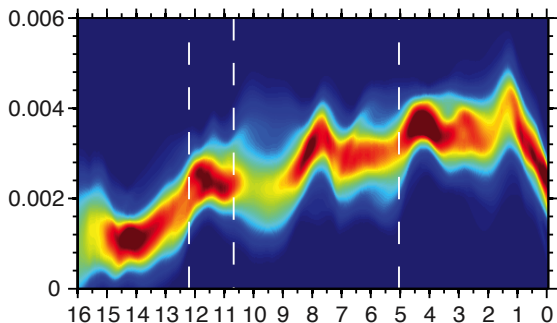

Age kyr cal BP

0

0.5

Figure 3: Density distribution of (A) biomass burned and (B) fire frequency proxies for 16 high-resolution records of south-western Europe (adapted from Vannière et al. 2016b). The colors represent the density of the proxy site-records at each time step; cold (blue and green) colors are indicative of highly dispersed data and thus capture the heterogeneity among sites; hot (yellow to dark red) colors indicate sites with homogeneous responses and thus spatial uniformity. The white dashed lines separate time periods with significant differences in the proxies' mean and variance. Ages are expressed in calibrated kiloyears before present (1950 CE).

Considering the amplitude of past climate changes and the occurrence of hundreds of major cultural transitions around the world, the paleofire community has much to add to these discussions, yet what makes forest fires gain media attention worldwide today is the socio-ecological context in which they occur. The expansion of private and commercial properties and infrastructure into the wildland-urban interface all but ensures future clashes between large-scale wildfires and an expanding human population. In addition, modern land management and resource exploitation, far removed from traditional land-use systems, has abruptly changed rates of fuel accumulation and fuel structure, often leading to fire-prone conditions in anthropogenic landscapes.

As an example, on the island of Corsica in the Mediterranean Sea, Lestienne et al. (2020) coupled data and models to show that currently, and likely for the first time in the Holocene, the fire regime is constrained by both climatic and anthropogenic factors. Climatic conditions may lead to events similar to the maxima in the paleofire record, but human activities may also increase their frequency. Moreover, these events will take place in very different ecosystems than in the past that are possibly not adapted to such events, therefore posing different levels of risk. At the beginning of the Holocene, summer climatic conditions promoted an extended fire season and large fires in pine forests. About 7000 years ago, climatic conditions became much less favorable for the natural spread of fires, and human land uses explain the recorded fire events. Today, based on the same criteria and markers, it appears that the conditions and length of the summer drought season are reaching levels equivalent to those at the beginning of the Holocene and may exceed them in the coming years. In addition to this, human pressure on ecosystems, as we know them today, is far greater compared to the beginning of the Holocene.

\section{Summary and outlook}

Over the past decade, the GPWG has contributed to the international community effort to understand present fire patterns in the context of the long-term changes, with:
- estimates of baseline trends and variability in fire regimes on orbital to decadal timescales and at regional to global spatial scales;

- the online sharing and public dissemination of all fire history data collated at https:// database.paleofire.org;

- data-model integration studies that have been used for future projection assessment based on long-term archive observations;

- the different roles of climate, humans, and vegetation as the co-drivers of past fire regimes;

- the development of projects that addressed challenges in conservation, restoration, and biodiversity maintenance under changing climate and land-use conditions;

- the growth and advancement of earlycareer paleofire scientists; and

- an emphasis on improving the dialog with fire managers and sustainable fire management practices.

Several key challenges remain for the global paleofire community. Many regions of the world remain insufficiently documented in terms of fire history and changing fire regimes through time (for example equatorial Africa and tropical environments). These knowledge gaps require further research to better inform the response to future environmental challenges in terms of how these systems will evolve with management that either includes or excludes policies regarding fire. The paleofire community must intensify efforts to identify knowledge gaps and promote research in critical regions of future change. Stimulating additional paleofire data generation, data synthesis, and novel research are imperative across the following themes:

- Investing in resources to implement new fire-proxy calibration in underrepresented regions, for example by promoting research activities and network building in Asia or Africa;

- A concerted effort of cross-disciplinary integration to promote more diverse knowledge for environmental policy assessment, particularly focusing on local/Indigenous knowledge (Colombaroli et al. 2019);

- Improving our understanding of global fire variability and impacts by integrating the existing fire database (https://database. paleofire.org) with modern observations in a way that can be accessed by other nonspecialists, including ecosystem managers and policy makers.

As the paleofire community moves forward, more investment in programs similar to PAGES' recently launched DiverseK working group (pastglobalchanges.org/diversek), which will pursue initiatives related to recent GPWG activities (Colombaroli et al. 2018), is critical. Finally, the PAGES-endorsed International Paleofire Network (https:// paleofire.org; Adolf et al. 2020) will make significant contributions toward addressing these challenges in the coming years.

\section{ACKNOWLEDGEMENTS}

The authors warmly thank all students and scientists who contributed to the GPWG's activities over the past 12 years.

\section{AFFILIATIONS}

${ }^{1} \mathrm{MSHE}, \mathrm{CNRS}$, Université Bourgogne Franche-Comté, Besançon, France

'Chrono-environnement, CNRS, Université Bourgogne Franche-Comté, Besançon, France

${ }^{3}$ Centre for Quaternary Research, Department of Geography, Royal Holloway University of London, UK ${ }^{4}$ Natural History Museum of Utah, University of Utah, Salt Lake City, USA

5Department of Geography, University of Utah, Salt Lake City, USA

\section{CONTACT}

Boris Vannière: boris.vanniere@univ-fcomte.fr

\section{REFERENCES}

Adolf C et al. (2020) PAGES Mag 28: 62

Aleman J et al. (2018) Fire 1: 7

Blarquez O et al. (2015) Sci Rep 5: 13356

Colombaroli D et al. (2014) Glob Change Biol 20: 2903-2914

Colombaroli D et al. (2019) Diverse knowledge informing fire policy and biodiversity conservation (policy brief). Royal Holloway University of London, 8 pp

Colombaroli D et al. (2018) PAGES Mag 26: 89

Connor S et al. (2019) Holocene 29: 886-901

Daniau AL et al. (2012) Global Biogeochem Cycles 26 GB4007

Dietze E et al. (2018). Quat Sci Rev 201: 44-56 Feurdean A et al. (2020) Biogeosciences 17: 1213-1230 Harrison SP et al. (2018) Earth Syst Dyn 9: 663-677 Lestienne M et al. (2020) Fire 3: 8

Marlon JR et al. (2008) Nat Geosci 1: 697-702 Marlon JR et al. (2013) Quat Sci Rev 65: 5-25 Marcisz Ket al. (2018) Open Quat 4: 1-7

Moritz MA et al. (2014) Nature 515: 58-66

Power M et al. (2008a) PAGES news 16: 39-40 Power M et al. (2008b) Clim Dyn 30: 887-907 Power M, Vannière B (2018) Quat Int 488: 1-2 Pyne S (2015) The fire age. Aeon, https://aeon.co/essays/

how-humans-made-fire-and-fire-made-us-human Vannière B et al. (2014) PAGES Mag 22: 40 Vannière B et al. (2016a) PAGES Mag 24: 31 Vannière B et al. (2016b) Quat Sci Rev 132: 206-212 Whitlock C et al. (2010) PAGES news 18: 53-96 Williams J (2013) Forest Ecol Manage 294: 4-10 